\title{
Занковский С.C.
}

Заслуженный юрист РФ, доктор юридических наук, профессор, главный научный сотрудник Института государства и права РАН.

\section{ГОСУДАРСТВЕННОЕ РЕГУЛИРОВАНИЕ БИЗНЕСА И ПРЕДПРИНИМАТЕЛЬСКОЕ ПРАВО}

\begin{abstract}
Аннотация
Государственное регулирование бизнеса рассмотрено в статье применительно $к$ малому, соииальному предпринимательству и некоторым аспектам таможенного регулирования. Показаны недостатки такого регулирования и варианты его совершенствования. Рассмотрены доктринальные и прикладные преимущества подхода к государственному регулированию бизнеса с позиций предпринимательского права.
\end{abstract}

Ключевые слова: государственное регулирование, предпринимательство, малое предпринимательство, социальное предприятие, таможенное регулирование, меры поддержки.

Keywords: state regulation, entrepreneurship, small business, social enterprise, customs regulation, support measures.

Концепция хозяйственного (предпринимательского) права, разработанная во второй половине прошлого века академиком РАН В.В. Лаптевым и возглавляемым им научным коллективом, если отвлечься от ее фундаментальной основы, отличается свойством, которого так не хватает современному законодательству — практичностью. В самом деле, если обратиться, например, к правовому регулированию малого предпринимательства, то окажется, что в ГК РФ оно вообще не отражено, за исключением упоминания о нем в ст. 1422 применительно к действиям, не являющимися нарушением исключительного права на селекционное достижение. В связи с этим попытка включить «Правовой статус субъектов малого предпринимательства» в паспорт специальности 12.00 .03 оказалась неубедительной по той причине, что малое предпринимательство приобрело свойства правового института не на поле гражданского права, а в результате закрепления в законе положений, относящихся к его государственному регулированию.

Среди этих положений, направленных на поддержку малого бизнеса, следует назвать законодательное определение условий отнесения к субъектам малого и среднего предпринимательства , сведения о которых внесены в единый реестр субъектов малого и среднего предпринимательства; оказание финансовой поддержки субъектам малого и среднего предпринимательства и организациям, образующим инфраструктуру поддержки субъектов малого и среднего предпринимательства за счет средств бюджетов субъектов Российской Федерации, средств местных бюджетов путем предоставления субсидий, бюджетных инвестиций, государственных и муниципальных гарантий по обязательствам субъектов малого и среднего предпринимательства и организаций, образующих инфраструктуру поддержки субъектов малого и среднего предпринимательства.

Гарантийная поддержка субъектов малого и среднего предпринимательства направлена на обеспечение доступа субъектов малого и среднего предпринимательства и (или) организаций, образующих инфраструктуру поддержки субъектов малого и среднего предпринимательства, к кредитным и иным финансовым ресурсам и оказывается участниками национальной гарантийной системы путем предоставления поручительств и (или) независимых гарантий по обязательствам субъектов малого и среднего предпринимательства и (или) организаций, образующих инфраструктуру поддержки субъектов малого и среднего предпринимательства, основанным на кредитных договорах, договорах займа, договорах финансовой аренды (лизинга), договорах о предоставлении банковской гарантии и иных договорах; обязательствам кредитных организаций, 
микрофинансовых организаций предпринимательского финансирования, иных юридических лиц, оказывающих финансовую поддержку субъектам малого и среднего предпринимательства; обязательствам специализированных финансовых обществ по выпуску облигаций, обеспеченных залогом прав (требований) по кредитным договорам, договорам займа и (или) иным обязательствам субъектов малого и среднего предпринимательства; иным обязательствам субъектов малого и среднего предпринимательства и (или) организаций, образующих инфраструктуру поддержки субъектов малого и среднего предпринимательства[1].

Далее к мерам поддержки следует отнести оказание имущественной поддержки субъектам малого и среднего предпринимательства, а также организациям, образующим инфраструктуру поддержки субъектов малого и среднего предпринимательства; информационной поддержки в виде создания федеральных, региональных и муниципальных информационных систем, официальных сайтов информационной поддержки субъектов малого и среднего предпринимательства в сети "Интернет" и информационно-телекоммуникационных сетей и обеспечения их функционирования в целях поддержки субъектов малого и среднего предпринимательства; консультационной поддержки; поддержки субъектам малого и среднего предпринимательства в сфере образования; в области инноваций и промышленного производства. Кроме того, Федеральным законом от 24.07.2007 N 209-Ф3 (ред. от 30.12.2020) "О развитии малого и среднего предпринимательства в Российской Федерации" (с изм. и доп., вступ. в силу с 01.01.2021) предусмотрена поддержка субъектов малого предпринимательства в отдельных сферах - ремесленной деятельности и внешнеэкономической деятельности. Отсюда видно, что малое и среднее предпринимательство как институт обязано своим появлением государственному регулированию бизнеса или, точнее, мерам его поддержки. И если предпринять попытку определить его статус с межотраслевых позиций гражданского и административного права, то этот единый по сути институт окажется разобщенным, либо такая попытка не будет представлять научного интереса.

Так, А.Б. Степин полагает, что субъекты малого предпринимательства находятся в сфере не только гражданских, но и административных отношений. Поэтому правовой статус не может ограничиваться только гражданско-правовым регулированием. В рамках административных отношений это выражается в применении положений ст.4.1.1 КоАП РФ, связанных с установлением правового статуса экономического субъекта. При наличии таких сведений и исходя из того, что исследуемый субъект привлекается к ответственности впервые при наличии иных условий, предусмотренных ст. 4.1.1 КоАП РФ, суд заменяет административное наказание в виде административного штрафа на предупреждение. В этом случае правовой статус малого предпринимательства является необходимым условием для реализации предусмотренной отдельной организационноправовой формой объема гражданских прав и обязанностей судебной и несудебной защиты, условий и порядка поддержки субъектов малого предпринимательства.

Но гражданское законодательство не содержит отдельной организационно-правовой формы малого предпринимательства, с которой были бы связаны гражданские права и обязанности, а условия и порядок поддержки субъектов малого предпринимательства лежат за рамками цивилистики.

Тот же автор утверждает, что правовой статус малого предпринимательства - это совокупность прав и обязанностей индивидуальных предпринимателей и юридических лиц, относящихся к субъектам малого предпринимательства, отражающих их отдельное правовое положение (состояние) и экономическую роль в развитии рыночных отношений[2].

Здесь дело в том, что «отдельное правовое положение» указанных субъектов никак не вытекает из гражданского законодательства, но вполне укладывается в рамки предпринимательского права, в котором отношения по регулированию предпринимательства и его осуществлению признаются едиными. Именно с позиций 
предпринимательско-правовой доктрины малое предпринимательство с учетом специфики его государственного регулирования образует отдельную разновидность среди субъектов предпринимательского права.

Аналогичный вывод следует сделать и в отношении социального предпринимательства. Классификация субъектов социального предпринимательства может быть проведена по ряду критериев, однако наиболее интересен тот, который был использован Департаментом предпринимательства и инновационного развития города Москвы и основан по существу на содержании деятельности таких субъектов и их кадровом составе.

Так, к 1 категории - трудоустройство социально уязвимых категорий населения (доля среди работников не менее 50\% (но не менее двух лиц), фонд оплаты труда не менее $25 \%)$

2 категория - реализация продуктов и услуг социально уязвимых категорий населения (доля доходов по итогам предыдущего года составляет не менее 50 \% в общем объеме, а доля полученной чистой прибыли за предшествующий год, направленная на осуществление такой деятельности в текущем году, составляет не менее $50 \%$ от размера указанной прибыли (в случае наличия чистой прибыли);

3 категория - производство товаров (работ, услуг) для социально уязвимых категорий населения в соответствии с определенными направлениями деятельности (доля доходов по итогам предыдущего года составляет не менее $50 \%$ в общем объеме, а доля полученной чистой прибыли за предшествующий год, направленная на осуществление такой деятельности в текущем году, составляет не менее $50 \%$ от размера указанной прибыли (в случае наличия чистой прибыли);

4 категория - деятельность, направленная на достижение общественно полезных целей и способствующая решению социальных проблем общества, из числа законодательно определенных видов деятельности (доля доходов по итогам предыдущего года составляет не менее $50 \%$ в общем объеме доходов, а доля полученной чистой прибыли за предшествующий год, направленная на осуществление такой деятельности в текущем году, составляет не менее $50 \%$ от размера указанной прибыли (в случае наличия чистой прибыли)[3].

Субъектный состав социального предпринимательства предопределен Федеральным законом от 24.07.2007 N 209-Ф3 (ред. от 27.10.2020) "О развитии малого и среднего предпринимательства в Российской Федерации"[4] где указано, что социальное предприятие - субъект малого или среднего предпринимательства, осуществляющий деятельность в сфере социального предпринимательства (п.8); под указанными субъектами тот же Закон понимает хозяйствующих субъектов (юридических лиц и индивидуальных предпринимателей), отнесенных к малым предприятиям, в том числе к микро предприятиям (п. 1).Иными словами, субъектный состав социальных предприятий включает коммерческие организации всех организационно-правовых форм и индивидуальных предпринимателей при условии их соответствия установленным Законом критериям.

Отсутствие для социальных предприятий особой, предусмотренной в ГК РФ организационно-правовой формы никак не влияет на их статус[5]. Дело в том, что организационно-правовая форма определяет внутреннее устройство юридического лица и характер его взаимоотношений с учредителями. Но базовые законодательные критерии, лежащие в основе социальных предприятий и создающие этот статус, относятся к кадровому составу его работников, роду занятий и направлениям использования получаемой прибыли; организационно-правовая форма в данном случае к таким критериям не относится.

Оказание поддержки социальным предприятиям может осуществляться в виде обеспечения наличия инфраструктуры поддержки социальных предприятий; оказания финансовой поддержки социальным предприятиям (в том числе в рамках предоставления 
субсидий); оказания имущественной поддержки социальным предприятиям (в том числе путем предоставления во владение и (или) в пользование государственного и муниципального имущества на льготных условиях); оказания информационной поддержки ; 5) оказания консультационной и методической поддержки (в том числе по вопросам привлечения финансирования и участия в закупках товаров, работ, услуг); содействия в развитии межрегионального сотрудничества, поиске деловых партнеров, в том числе путем проведения ярмарок, деловых конгрессов, выставок, а также обеспечения участия социальных предприятий в указанных мероприятиях на территориях субъектов Российской Федерации и на территориях муниципальных образований; организации профессионального обучения, профессионального образования, дополнительного профессионального образования и содействия в прохождении независимой оценки квалификации работников социальных предприятий в соответствии с законодательством Российской Федерации; реализации иных мер (мероприятий) по поддержке социальных предприятий, которые предусмотрены федеральными законами, принимаемыми в соответствии с ними иными нормативными правовыми актами Российской Федерации, а также законами и иными нормативными правовыми актами субъектов Российской Федерации, муниципальными правовыми актами[5].

Отраслевой характер социального предпринимательства определяется его принадлежностью к предпринимательскому праву, причем не в том его понимании, которое видит в нем бизнес-часть цивилистики. В последней для такого предпринимательства не оказалось места, поскольку ни ГК РФ, ни принятые в его развитие федеральные законы в силу отраслевых рамок гражданского права не вторгаются в сферу государственного регулирования экономики и никак не выделяют хозяйствующих субъектов в зависимости от области их деятельности. Между тем, социальное предпринимательство получило свой статус именно по той причине, что федеральный законодатель предусмотрел для лиц, им занимающихся, ряд мер государственной поддержки. Без них определение в законе такого предпринимательства и его субъектного состава не имело бы ни малейшего смысла.

Социальное предпринимательство лежит в сферах т. н. горизонтальных, т. е. договорных отношений, которые позволяют продавать продукцию и услуги социально уязвимых категорий населения, либо производить и продавать предназначенную для них продукцию, а также вертикальных отношений, т. е. отношений по государственному регулированию экономики. Все это укладывается в разработанную академиком РАН В.В. Лаптевым и его последователями концепцию хозяйственного (предпринимательского) права, по которой хозяйственное право представляет собой совокупность правовых норм, определяющих порядок руководства и осуществления хозяйственной деятельности и регулирующих хозяйственные отношения между организациями[1].

В центре правового регулирования социального предпринимательства стоит уже упоминавшийся Федеральный закон от 24.07.2007 N 209-Ф3 (ред. от 27.10.2020) "О развитии малого и среднего предпринимательства в Российской Федерации». Им определены все основные правовые параметры такого предпринимательства и в то же время субъектам Российской Федерации в целях признания субъектов малого и среднего предпринимательства социальными предприятиями предоставлено право устанавливать категории граждан и виды деятельности дополнительно к категориям, предусмотренным в указанном Законе. Однако оказание поддержки субъектам малого и среднего предпринимательства, признанным социальными предприятиями с учетом дополнительно установленных субъектами Российской Федерации категорий граждан и видов деятельности осуществляется за счет бюджетных ассигнований бюджетов субъектов Российской Федерации и (или) местных бюджетов.

Остановимся теперь на такой важной форме государственного воздействия на экономику, как таможенное регулирование, имеющее прямое значение и для сферы ценообразования. 
Речь идет о спорах, возникающих как в России, так и в пределах Евразийского экономического союза в связи с внесением компетентными государственными органами изменений в Единую товарную номенклатуру внешнеэкономической деятельности ЕЭС и Единый таможенный тариф ЕЭС, в связи с чем у хозяйствующего субъекта возникает обязанность по уплате таможенных платежей в большем размере.

При решении вопроса о правомерности таких изменений основное внимание следует уделить их соответствию Международной конвенции о гармонизированной системе описания и кодирования товаров, принятой в Брюсселе 14 июня 1983 г.[6] При этом следует исходить из того, что Гармонизированная система описания и кодирования товаров является международной основой Товарной номенклатуры внешнеэкономической деятельности ЕАЭС. Поэтому все государства - члены ЕАЭС участвуют в названной Конвенции и учитывают в своей правоприменительной практике ее положения, а также пояснения к Гармонизированной системе.

Такой подход основан на действующем законодательстве. Так, среди понятий, сопутствующих принципам функционирования таможенного союза, Гармонизированная система описания и кодирования товаров Всемирной таможенной организации названа в качестве основания единой Товарной номенклатуры внешнеэкономической деятельности Евразийского экономического союза ( ст. 25 Договора о Евразийском экономическом союзе)[7].

Аналогичное правило содержится в Таможенном кодексе Евразийского экономического союза, где указано, что международной основой Товарной номенклатуры внешнеэкономической деятельности являются Гармонизированная система описания и кодирования товаров Всемирной таможенной организации и единая Товарная номенклатура внешнеэкономической деятельности Содружества Независимых Государств (п. 2 ст. 19).

Данное положение воспринято практикой. Так, в решении Суда[8] Евразийского экономического союза от 21.06.2016 N CE-1-2/2-16-АП «Об оставлении без изменения Решения Суда Евразийского экономического союза от 04.04.2016, которым было оставлено без удовлетворения заявление о признании решения Евразийской экономической комиссии от 18.07.2014 N 117 "О классификации холодильной машины "чиллер" по единой Товарной номенклатуре внешнеэкономической деятельности Таможенного союза" не соответствующим международным договорам в рамках Евразийского экономического союза» констатировано, что прямая отсылка в праве Союза к Гармонизированной системе свидетельствует, что последняя обязательна к применению. Для судопроизводства по спорам в рамках ЕАЭС это означает, что при проверке оспариваемого решения Евразийской экономической комиссии Суд также вправе проверить его на соответствие Гармонизированной системе.

Верховный Суд РФ полагает, что Международная Конвенция по Гармонизированной системе описания и кодирования товаров возлагает на Российскую Федерацию как государство - участника данного международного договора обязанность обеспечивать соответствие применяемых таможенно-тарифных и статистических номенклатур Гармонизированной системе[9].

Обязательность применения Гармонизированной системы в Российской Федерации, кроме того, вытекает из пункта 2 статьи 25 Договора о Евразийском экономическом союзе, согласно которому Гармонизированная система описания и кодирования товаров Всемирной таможенной организации является основой товарной номенклатуры внешнеэкономической деятельности Евразийского экономического союза.

Было подчеркнуто также, что применение Гармонизированной системы включает в себя обязательное использование ее Основных правил интерпретации (пункт 1 статьи 3 Конвенции).

Не менее важен вывод Верховного Суда РФ о том, что участники внешнеэкономической деятельности имеют правомерные ожидания в отношении того, что 
осуществляемая в соответствии с Гармонизированной системой классификация товаров, имеющая значение, в том числе, для определения размера таможенных платежей, будет носить объективный, предсказуемый и прозрачный характер, унифицированный в большинстве государств мира, и не будет зависеть от усмотрения таможенных органов, что являлось бы недопустимым в публичных правоотношениях.

С учетом изложенного, немотивированный отказ судов учитывать при разрешении спора разъяснения Всемирной таможенной организации, на которые полагалась коммерческая организация при обращении в таможенный орган, не могут быть признаны правильными[8].

В Постановлении Пленума Верховного Суда РФ от 26.11.2019 N 49 "О некоторых вопросах, возникающих в судебной практике в связи с вступлением в силу Таможенного кодекса Евразийского экономического союза" обращено внимание на то, что при разрешении споров, вызванных неоднозначностью возможных вариантов классификации товаров, суды могут принимать во внимание рекомендации и разъяснения по классификации, данные Всемирной таможенной организацией в соответствии со статьей 7 Конвенции, относимые к спорным товарам и в отношении которых Российская Федерация не заявила об отказе в их применении.

Изложенное приводит к выводу о том, что в спорах, о которых шла речь, основное значение имеет вопрос о соответствии действий Евразийской экономической комиссии и ее органов положениям Международной конвенции о гармонизированной системе описания и кодирования товаров.

Важнее, однако, другое. Государственное регулирование бизнеса, как видно из предыдущего изложения, в ряде случаев построено не лучшим образом, что видно на примере социального предпринимательства, которое оказалось привязано к малому предпринимательству, хотя в этой сфере вполне может участвовать и крупный бизнес. Нужен, следовательно закон о социальном предпринимательстве, в котором можно было бы предусмотреть как вопросы его государственного регулирования, так и правового статуса, а также особенности участия в хозяйственном обороте.

Но если смотреть на проблему шире, то становится очевидным целесообразность постановки вопроса о принятия на федеральном уровне законодательного акта, посвященного государственному воздействию на бизнес, в котором нашли бы отражение принципы такого воздействия и его пределы. Это позволило бы скорректировать сложившиеся на сегодня положение, когда государственное регулирование предпринимательства разобщено и не подчинено указанным принципам.

Работа выполнена при информационной поддержке СПС «КонсультантПлюс»

\section{Литература}

1. Лаптев В.В. Предпринимательское (хозяйственное) право. Избранные труды.

Екатеринбург. 2008.

2.Степин А.Б. Правовой статус субъектов малого предпринимательства // Юрист. 2019. N

9. С. 19 - 24.

3. Официальный портал Мэра и Правительства Москвы. Интернет ресурс: https://clck.ru/Rxr73

4."Собрание законодательства РФ", 30.07.2007, N 31, ст. 4006.

5. Васильева К.В. Социальное предпринимательство узаконено: что дальше? //

Безопасность бизнеса. 2020. N 1.

6."Товарная номенклатура внешнеэкономической деятельности СНГ" (ТН ВЭД СНГ), Издание 2-е. - М., 1996.

7.Официальный интернет-портал правовой информации http://www.pravo.gov.ru, 16.01.2015. 